\title{
Host attraction and biting behaviour of Anopheles mosquitoes in South Halmahera, Indonesia
}

\author{
Brandyce St. Laurent ${ }^{1,6^{*}}$ (D) Timothy A. Burton ${ }^{1}$, Siti Zubaidah², Helen C. Miller ${ }^{1}$, Puji B. Asih², \\ Amirullah Baharuddin ${ }^{5}$, Sully Kosasih2, Shinta ${ }^{5}$, Saya Firman', William A. Hawley 3,4, Thomas R. Burkot 3,7, \\ Din Syafruddin ${ }^{2}$, Supratman Sukowati ${ }^{5 \wedge}$, Frank H. Collins ${ }^{1}$ and Neil F. Lobo ${ }^{1}$
}

\begin{abstract}
Background: Indonesia is home to a variety of malaria vectors whose specific bionomic traits remain largely uncharacterized. Species-specific behaviours, such as host feeding preferences, impact the dynamics of malaria transmission and the effectiveness of vector control interventions.

Methods: To examine species-specific host attraction and feeding behaviours, a Latin square design was used to compare Anopheles mosquitoes attracted to human, cow, and goat-baited tents. Anopheles mosquitoes were collected hourly from the inside walls of each baited tent. Species were morphologically and then molecularly identified using rDNA ITS2 sequences. The head and thorax of individual specimens were analysed for Plasmodium DNA using PCR. Bloodmeals were identified using a multiplex PCR.

Results: A total of 1024, 137, and 74 Anopheles were collected over 12 nights in cow, goat, and human-baited tents, respectively. The species were identified as Anopheles kochi, Anopheles farauti s.s., Anopheles hackeri, Anopheles hinesorum, Anopheles indefinitus, Anopheles punctulatus, Anopheles tessellatus, Anopheles vagus, and Anopheles vanus, many of which are known to transmit human malaria. Molecular analysis of blood meals revealed a high level of feeding on multiple host species in a single night. Anopheles kochi, An. indefinitus, and An. vanus were infected with Plasmodium vivax at rates comparable to primary malaria vectors.
\end{abstract}

Conclusions: The species distributions of Anopheles mosquitoes attracted to human, goat, and cow hosts were similar. Eight of nine sporozoite positive samples were captured with animal-baited traps, indicating that even predominantly zoophilic mosquitoes may be contributing to malaria transmission. Multiple host feeding and flexibility in blood feeding behaviour have important implications for malaria transmission, malaria control, and the effectiveness of intervention and monitoring methods, particularly those that target human-feeding vectors.

Keywords: Anopheles, Indonesia, Malaria, Biting behavior, Host attraction, Vector ecology

\section{Background}

Indonesia is a large and geographically diverse country with more than 30 Anopheles species. Malaria prevalence varies among climates and locales, with an estimated $25 \%$

\footnotetext{
*Correspondence: brandyce.stlaurent@nih.gov

$\wedge$ Deceased

${ }^{6}$ Laboratory of Malaria and Vector Research, National Institute of Allergy and Infectious Diseases, National Institutes of Health, Bethesda, MD, USA Full list of author information is available at the end of the article
}

of the human population residing in malaria endemic areas and an estimated 1.3 million cases of malaria in 2015 [1, 2]. Many of the resident Anopheles species are members of cryptic species complexes whose distribution and ecology are not well known $[3,4]$. Characterizing the malaria vector species composition in Indonesia is critical to determine suitable methods for collection and the potential impact of interventions that exploit vector feeding behaviours. Multiple host feeding and flexibility in feeding behaviour may enable species to 
bypass the most common malaria control interventions, such as insecticide treated nets (ITNs) or indoor residual spray (IRS) which are centered around indoor and nighttime biting anthropophilic Anopheles [5]. Generalist host feeding behaviours can also contribute to the spread of viral zoonotic diseases of which humans are incidental hosts, such as West Nile Virus and Japanese encephalitis. Species-specific host attraction, biting preference, and the densities of available hosts may be important for the contribution of any one Anopheles species to local malaria transmission [6, 7]. Additionally, species that are opportunistic in host selection may be deterred from biting humans if adequate numbers of other hosts are available, with a consequent effect on reducing malaria transmission $[8,9]$.

Host choice experiments can help describe the relative attractiveness of different host species to mosquitoes. Host feeding is a complex behaviour and is likely determined by a combination of both innate host preferences and ecological factors, such as host seeking behaviour $[10,11]$ and host availability, including defensive behaviour [12-14]. The rate of human biting is a critical component of calculating vectorial capacity, an important epidemiological measure of how much a particular vector is capable of contributing to malaria transmission [15]. Human biting rates are most frequently measured using human landing collections or other types of human-baited traps [16-19], and human preference is evaluated by testing the relative attraction of humans to another animal by comparing capture rates in paired tent traps $[20,21]$. Feeding success rate is measured by comparing the sources of bloodmeals in captured mosquitoes [22-25]. These measures and other host and local factors are useful in understanding mosquito feeding preferences and behaviour [26].

The bionomics of Anopheles species that act as secondary vectors and sustain malaria transmission become increasingly important when considering malaria elimination strategies. In addition to prompt diagnosis and treatment of human infections, it is clear that for outdoor biting, zoophilic vectors, like most members of the Anopheles punctulatus complex, there is a need for alternative methods of malaria control [27]. One potential approach to target mosquitoes that feed on non-human hosts is the use of endo-insecticides such as ivermectin $[28,29]$. Ivermectin has been shown to reduce populations of some vectors in the south Pacific region, and may be more effective against zoophilic vectors [30]. Other methods of zooprophylaxis have been evaluated in Indonesia and shown to have some potential for control [8]. If Anopheles populations frequently feed on non-human hosts, interventions focused on or near cattle or other animals may be effective for reducing the contribution of these typically zoophagic or generalist feeding species to malaria transmission [31]. To establish which control measures would be most effective in an environment with multiple vectors, species-specific feeding behaviours must be clearly defined. In this study the feeding behaviours of Anopheles species were assessed by evaluating their attraction to cow, goat, and human hosts. If the sub-populations of Anopheles transmitting malaria also bite animals, animal-baited traps could be a useful and cost effective tool for monitoring vector populations.

\section{Methods \\ Site description}

This study was conducted in Saketa village, South Halmahera, in the northern Maluku islands of Indonesia. Villages are primarily coastal with houses constructed of wood and plaster with corrugated metal roofs and open eves which could provide access for mosquito entry, though indoor catches in this area have indicated limited house entering (N. Lobo, unpublished data). Saketa village is a fishing village located on the coast adjacent to heavily forested hills and has a population of roughly 5000 people. Grazing animals were held in large open fenced areas or allowed to roam freely, with an observed tendency to cluster on the periphery of the village. The primary forms of malaria mosquito control in South Halmahera are ITNs and larval habitat management. The northern Maluku islands have a rainy season from November to March. South Halmahera had some of the higher reported malaria rates in the region during the time of this study, with stable endemic transmission of Plasmodium falciparum and Plasmodium vivax [2, 32, 33].

\section{Study design}

A Latin square design was used to compare catches of Anopheles attracted to human, cow, and goat-baited tents. The traps consisted of large screened tents approximately $3 \mathrm{~m} \times 5 \mathrm{~m}$ and $2 \mathrm{~m}$ high (Insta-Clip, Six-sided Screen House, The Coleman Company, Inc.). One tent was used for each host. Each tent had six screened sides with two sides left completely open for mosquito entry. Humans acting as a host were protected within a small closed tent (REI "bug hut") set inside the larger tent (Coleman $15 \times 13$ instant screen house). The animals in the cow and goat-baited traps were readily accessible for feeding by mosquitoes entering the trap and adult animals were used in the study. The use of host-baited tents to capture Anopheles mosquitoes was validated in an evaluation of sampling methods in three sites in Indonesia (MTC, unpublished), where goat-baited tents captured more Anopheles than either HLCs or human-baited tents. The baited tents were stationed more than $50 \mathrm{~m}$ 
apart and at least $25 \mathrm{~m}$ from other potential hosts. The hosts were rotated nightly through three stations for 12 nights (e.g., each host species occupied each of the 3 stations for 4 nights) in August, 2010 (during the rainy season). Resting mosquitoes were collected from the inside walls of baited tents every hour from 18:00 to 6:00 h by mouth aspiration. Human collectors were advised not to wear any insect repellants or smoke. Hourly collections were held in cups labeled by hour until processed.

\section{Sample processing}

Specimens were morphologically identified using regional keys [34], mosquitoes were dissected for parity and abdominal status was recorded in the field. Samples were stored individually in $1.5 \mathrm{ml}$ tubes and labelled with collection information and a unique identifier. This information was later paired with collection information recorded on sample forms. Samples were homogenized in a 2\% CTAB (Cetyl Trimethyl Ammonium Bromide) extraction buffer, and DNA was extracted with phenol and isopropanol before precipitation with ethanol. The ribosomal DNA internal transcribed spacer region two (rDNA ITS2) region was isolated with PCR using primers developed for differentiating other Anopheles species complexes [35]. The ribosomal DNA internal transcribed spacer region two (ITS2) was amplified from genomic DNA using the ITS2A (5'-TGTGAACTGCAGGACACAT- $3^{\prime}$ ) and ITS2B (5'-TATGCTTAAATTCAGGGGGT-3') primers [35]. Each reaction contained $2.5 \mu \mathrm{l}$ of $10 \times$ buffer, $200 \mu \mathrm{M}$ of each dNTP, 0.5 units of Taq DNA polymerase, $0.75 \mu \mathrm{l}$ of $10 \mathrm{pmol} /$ $\mu \mathrm{l}$ of forward and reverse primers, and $2 \mu \mathrm{l}$ of the prepared DNA template. The thermocycling conditions were as follows: $94{ }^{\circ} \mathrm{C}$ for $5 \mathrm{~min}, 30$ cycles of denaturation at $94{ }^{\circ} \mathrm{C}$ for $1 \mathrm{~min}$, annealing at $52^{\circ} \mathrm{C}$ for $1 \mathrm{~min}$, and extension at $72{ }^{\circ} \mathrm{C}$ for $2 \mathrm{~min}$, with a final extension at $72{ }^{\circ} \mathrm{C}$ for 5 min.

The presence of amplified fragments was confirmed by electrophoresis on a 1\% agarose gel. An enzyme cleanup was used to purify each PCR product: $2 \mathrm{U}$ of Exonuclease 1 (USB Corporation, Cleveland, OH, USA), $1 \mathrm{U}$ of Shrimp Alkaline Phosphatase (USB), and $1.8 \mu \mathrm{l}$ of ddH20 were added to $8 \mu \mathrm{l}$ of PCR product. This mixture was incubated at $37{ }^{\circ} \mathrm{C}$ for $15 \mathrm{~min}$, followed by $15 \mathrm{~min}$ at $80{ }^{\circ} \mathrm{C}$ to inactivate the enzymes. Purified PCR products were sequenced directly using Sanger sequencing on ABI 3730 xl DNA Analyzer platform (Applied Biosystems).

\section{Blood meal typing and screening for Plasmodium}

Blood meals of visibly blood-fed specimens were analysed using a multiplex blood meal diagnostic PCR assay based on vertebrate mitochondrial DNA sequences [22] using cow, human, and goat-specific primers. Blood meals that did not match these species were sequenced using the universal forward and reverse primers of this PCR assay to identify the host blood meal source. A subset of 350 specimens was analysed for Plasmodium infection using the standard CDC sandwich ELISA test for the detection of $P$. falciparum, $P$. vivax-210, and $P$. vivax-247 circumsporozoite (CS) proteins [36], and a confirmatory multiplex PCR for P. falciparum and P. vivax [37].

\section{Analysis}

Sequences were aligned using Seqman assembler (Lasergene $v$ 8.1.5) to evaluate genetic variation, and identical sequences were grouped into contigs. The consensus sequences of these contigs were blasted against the NCBI (National Center for Biotechnology Information) database with BLASTn for confirmation of molecular species identification. Statistical analyses were performed using R version 3.3.1 (Vienna, Austria) [38]. Figures were generated using the ggplot2 and RColorBrewer packages within $\mathrm{R}$ version 3.3.1 [38-40].

\section{Results}

Anopheles mosquitoes of nine morphologically identified species were captured $(\mathrm{n}=1235)$ during 12 catch-nights in August 2010 in Saketa village, Halmahera. These morphological species were Anopheles farauti, Anopheles hackeri, Anopheles indefinitus, Anopheles kochi, Anopheles punctulatus, Anopheles subpictus, Anopheles tessellatus, Anopheles vagus, and Anopheles vanus; many of which are considered vectors of human Plasmodium [3, 41]. Ribosomal ITS2 sequence analysis of specimens revealed a low concordance between molecular and morphological identifications. Of 1014 specimens that were molecularly identified, 354 (34.9\%) were discordant from the morphological identification (Table 1). Molecularly identified species were An. kochi (321), An. farauti s.s. (1), An. hackeri (1), An. hinesorum (18), An. indefinitus (112), An. punctulatus (2), An. tessellatus (4), An. vagus (514), and An. vanus (41). Five of these species were found in all three host-baited tents in similar proportions (Table 2). Morphologically identified An. hackeri and $A n$. vanus had not been previously sequenced. These sequences have been submitted to GenBank. ITS2 sequences within each molecular species were identical, and hereafter, the "species" name will refer to molecularly identified species. Five of nine molecular species (eight of nine by morphological ID) were captured on each of the three hosts (Table 2).

Blood meal analysis revealed that Anopheles of three of the nine species, An. indefinitus, An. kochi, and An. vagus, had fed on all 3 host species (Additional file 1: Table S1). 8.6\% (93 of 1088) of blood-fed Anopheles contained blood from more than one host species (Table 3). 


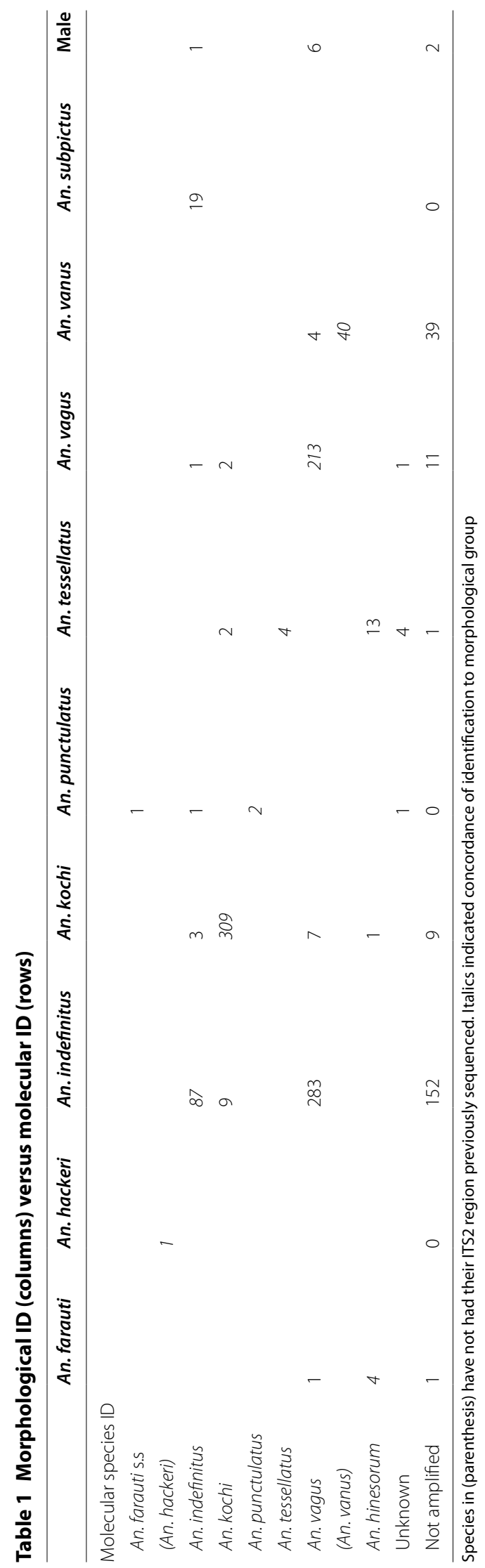


Table 2 Molecular species identification of mosquitoes caught in three host-baited traps

\begin{tabular}{|c|c|c|c|c|}
\hline \multirow[t]{2}{*}{ Molecular identification } & \multicolumn{4}{|c|}{ Host baited tent } \\
\hline & Cow & Goat & Human & Total \\
\hline (An. hackeri) & 1 & & & 1 \\
\hline (An. vanus) & 32 & 6 & 2 & 40 \\
\hline An. farauti s.s. & & 1 & & 1 \\
\hline An. hinesorum & 14 & 2 & 2 & 18 \\
\hline An. indefinitus & 99 & 10 & 3 & 112 \\
\hline An. kochi & 267 & 42 & 13 & 322 \\
\hline An.punctulatus & & & 2 & 2 \\
\hline An. tessellatus & 4 & & & 4 \\
\hline An. vagus & 448 & 38 & 28 & 514 \\
\hline Unknown & 4 & 1 & 1 & 6 \\
\hline Total & 869 & 100 & 51 & 1020 \\
\hline
\end{tabular}

Total molecularly confirmed specimens in each host-baited tent are $n=865$ in the cow-baited tent, $n=99$ in the goat-baited tent, and $n=50$ in the human tent

Table 3 Bloodmeal identification of molecularly confirmed species

\begin{tabular}{lccrr}
\hline & \multicolumn{4}{l}{ Host baited tent } \\
\cline { 2 - 5 } & Human & Goat & Cow & Total \\
\hline Single blood meal & 2 & 3 & 2 & 7 \\
$\quad$ Human & 12 & 38 & 38 & 88 \\
Goat & 29 & 37 & 834 & 900 \\
Cow & & & & \\
Mixed blood meals & 5 & 13 & 59 & 77 \\
Cow + goat & 3 & 3 & 8 & 14 \\
Cow + human & 1 & 1 & 0 & 2 \\
Goat + human & 52 & 95 & 941 & 1088 \\
Total & 11.5 & 7.4 & 1.1 & $2.1 \%$ \\
Human fed (\%) & 17.3 & 17.9 & 7.1 & $8.5 \%$ \\
Mixed bloodmeals (\%) & & & & \\
\hline
\end{tabular}

Rates of human and mixed bloodmeals as percentages of total per host tent are shown. Human containing bloodmeals are in italics

19.7\% of blood meals $(n=214)$ contained blood from a host other than the host in the tent where the mosquito was captured. The percentage of human-fed females was higher in the human and goat-baited tents, 11.5 and $7.4 \%$ respectively, with a much lower proportion of human-fed females in the cow-baited tent, 1.1\% (Table 3). Counting mixed blood meals as two separate blood meals, blood feeding rates of total Anopheles analysed were: human $2 \%$, goat $14 \%$, and cow $84 \%$ (Table 3 ). Human blood index could not be calculated from this data as the relative numbers of cows, goats, and humans in the village were not tallied.
The total Anopheles catch for each host-baited tent was compared using ANOVA and a post hoc Tukey's HSD test. The cow-baited tent caught significantly more Anopheles $(\mathrm{n}=1024)$ per night than either the goat or human baited tents (Fig. 1; $p<0.001$ ). Anopheles numbers captured in the human and goat-baited tents were not significantly different from each other, with 74 and 137 Anopheles, respectively. Numbers of Anopheles were not significantly affected by location $(p=0.325)$ or night of capture $(p=0.470)$.

The majority of specimens in each host-baited tent were captured before $2200 \mathrm{~h}$ (Fig. 2a). Entry of An. vagus and $A n$. kochi, the two most abundant species, into the tents peaked from 1900 to 2100 (Fig. 2b). Nine male Anopheles were collected, 6 in the cow-baited tent, two in the goat-baited tent, and one in the human-baited tent. Six of the males were molecularly identified as An. vagus, and one was An. indefinitus, with two unknowns.

A subset of 350 specimens were analysed using a sandwich ELISA for CS protein [36] and by PCR for Plasmodium DNA [37]. Of 336 specimens successfully analysed, $9(2.7 \%)$ were positive for Plasmodium vivax DNA (Table 4) and no samples were found positive for P. falciparum. Six of the $P$. vivax positive specimens were identified as An. kochi; four collected in the cow-baited tent and two collected in the goat-baited tent. The other positive samples were An. indefinitus $(\mathrm{n}=1)$ and An. vagus $(\mathrm{n}=1)$ captured in the goat-baited tent, and a morphologically identified $A n$. barbirostris $(\mathrm{n}=1)$ captured in the human-baited tent. Six of 69 (8.95\%) An. kochi and 1 of $10 \mathrm{An}$. vagus analysed were positive for Plasmodium DNA.

\section{Discussion}

In a single village in South Halmahera, Indonesia, Anopheles mosquitoes captured in human, goat, and cow-baited tents were compared to determine species-specific host attraction and feeding behaviour. Nine Anopheles species were molecularly identified in these collections: $A n$. kochi, An. farauti s.s., An. hackeri, An. hinesorum, An. indefinitus, An. punctulatus, An. tessellatus, An. vagus, and An. vanus (Table 1). Additionally, bloodmeals of fed mosquitoes were typed and mosquitoes were analysed for the presence of Plasmodium spp. sporozoites. Frequent multiple host-feeding within a single night and flexibility in host choice within Anopheles species were observed.

There was a large discrepancy between morphological and molecular Anopheles species identifications, with $35 \%$ of specimens showing discordance between morphological and molecular identifications (Table 1). This could likely be the result of the presence of many cryptic species complexes and high Anopheles diversity in the country. Some species may have overlapping 


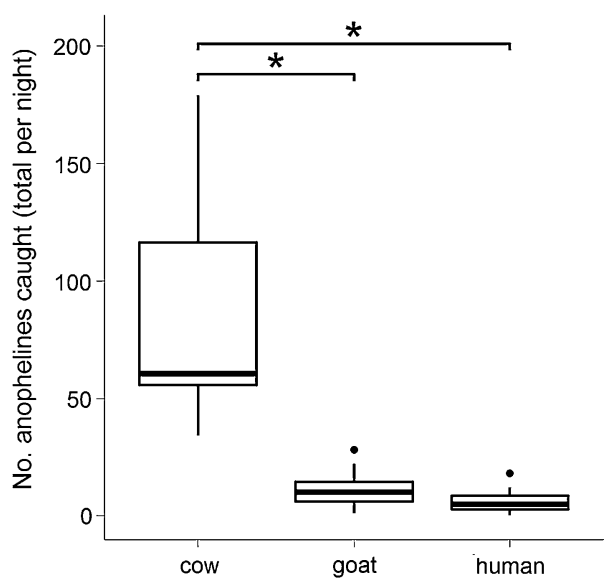

Fig. 1 Number of mosquitoes caught per trap over all nights. Total specimens caught in each host-baited tent are $n=1024$ in the cow-baited tent, $n=137$ in the goat-baited tent, and $n=74$ in the human tent
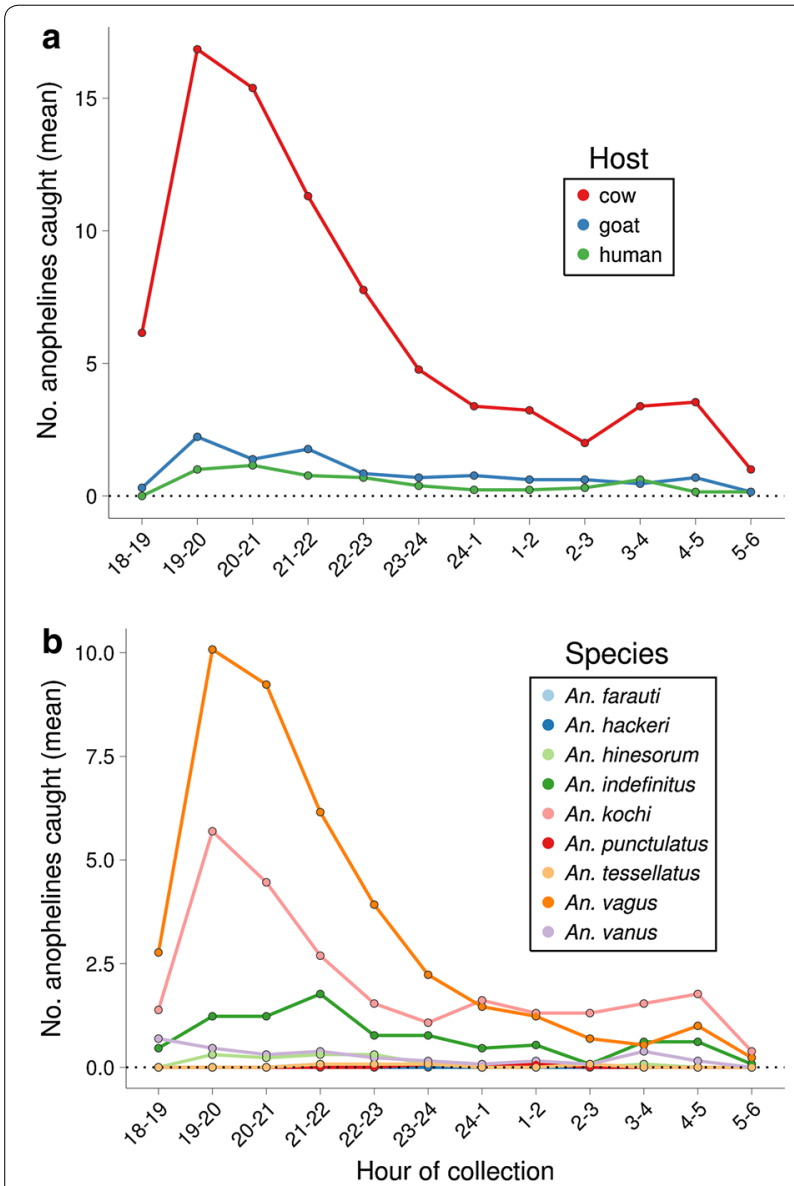

Fig. 2 Hourly biting behaviour by host bait and species. a Total Anopheles by hour by host baited tent. $\mathbf{b}$ Total number of molecular species by hour. For most species, an early evening peak of activity was observed around 7-8 pm in all of the tents, a time when people are outdoors and active or inconsistent morphological characteristics that confuse species identifications [42, 43]. Characterizing these traits may uncover vulnerabilities in vector populations, outside of well understood and more easily exploited anthropophilic or endophilic behaviours that may be targeted for control.

A pilot experiment, using an empty tent as a control, showed that Anopheles did not enter and rest on the walls of an empty tent. An experiment evaluating other human-baited trapping techniques showed that Anopheles would not enter tents with restricted openings, such as the Ifakara tent trap ${ }^{1}$ [44]. Further, few males ( 9 of 1235) were captured in any of the tents, indicating that the host-baited tents selectively capture females where the presence of the host was attractive, whether they were actively host-seeking or had just fed. $24 \%$ of female Anopheles were unfed in the human-baited tent, in which the human was protected, whereas the goat or cowbaited tents contained only 18 and 5\% unfed females, respectively (Table 3). Anopheline mosquitoes collected in a particular host-baited tent were expected to have fed on that host. The human hosts were protected under a smaller tent within the large tent, suggesting that the bloodfed mosquitoes captured in that tent had fed prior to entering. Mixed host blood meals might also indicate that mosquitoes entering the tents could have fed or partly fed on another host before entering the tent. High numbers of females partially fed on human hosts has been observed in other vectors, possibly due to increased disturbance when feeding on humans [21]. The increased feeding success on cow baits may contribute to greater numbers of Anopheles resting on inner walls of the cowbaited tents.

The species found positive for $P$. vivax sporozoites (An. kochi, An. vagus, An. indefinitus, and An. vanus) are not considered to be primary malaria vectors (Table 4). All sporozoite positive specimens were positive for $P$. vivax, consistent with studies that report that most of the malaria in this area is due to $P$. vivax $[45,46]$. The majority of the $P$. vivax positive specimens were collected in the animal-baited tents. Further evaluation is needed to clarify which Anopheles species are acting as primary vectors and whether designations of "zoophagic" and "anthropophagic" are really applicable to the anophelines in this region in relation to monitoring and control. In this study, seemingly zoophagic vectors are feeding on both human and animal hosts and carrying Plasmodium parasites, potentially playing an important role in transmission.

${ }^{1}$ Co-submitted paper: Comparative Evaluation of Anopheline Sampling Methods in Three Localities in Indonesia 
Table 4 Sporozoite positive mosquitoes

\begin{tabular}{llllc}
\hline Molecular species ID & Host-baited tent & Blood meal ID & Positive/total & Sporozoite rate (\%) \\
\hline An. indefinitus & Goat & Goat & $1 / 28$ & 3.57 \\
An. kochi & Goat & Unfed & $6 / 67$ & 8.95 \\
& Cow & Cow & & \\
Cow & Cow & & \\
& Cow & Cow & & \\
& Cow & Cow & $1 / 206$ & 0.49 \\
An. vagus & Goat & Unfed & $1 / 10$ & 10.0 \\
An. vanus & Goat & Cow + goat & \\
\hline
\end{tabular}

Nine mosquito specimens of 336 analysed by CS ELISA and PCR for sporozoite antigens were found positive for Plasmodium vivax. None of the nine positive specimens were discordant between morphological and molecular identification

More Anopheles mosquitoes were captured during the 12 nights of this experiment than by separate longitudinal sampling over the proceeding 2 years using HLCs in the same location (N. Lobo, pers. comm..), indicating zoophagic behaviours of the local vector population. Five of nine molecular species were found in all three traps (Table 2). The cow-baited tent seemed to be particularly effective for collecting Anopheles throughout the night and molecular analysis showed that these were the same species that were biting humans. Eight of nine Plasmodium positive Anopheles were captured in the animal-baited tents (Table 4). This result is consistent with the presence of a single population of mosquitoes in each species that shows behavioural plasticity in host species selection for blood meals, suggesting that trapping using animal baits may be an effective tool for monitoring malaria vectors. Previous evaluation of trapping techniques in this area showed that a goat-baited tent caught significantly more Anopheles than either a human-baited tent or human landing collections in the same village (See footnote 1). An additional variable, the effect of host size in attracting Anopheles mosquitoes, may be operating. Larger hosts have been shown to be more attractive to Anopheles [47, 48]. Mosquitoes attracted to long-range host cues such as $\mathrm{CO}_{2}$ and chemical volatiles may encounter more of an attractive signal from a large mammal such as a cow than a human or goat $[7,14,49]$. However, this study examined the attractiveness of single adult host-baits rather than weight or $\mathrm{CO}_{2}$ equivalent hosts per tent. The cow-baited tents were significantly more attractive than either the goat or human tents. Host size was likely not the only factor, since the goats used were much smaller than humans and a single goat attracted many more Anopheles per night than a single human host.

The majority of species found in this study ( 5 of 9 species) were attracted to multiple animal hosts (Table 2). Molecular identification of all Anopheles revealed that there were similar species distributions of mosquitoes attracted to human, goat, and cow hosts and a similar distribution of species feeding on those hosts (Table 2; Additional file 1: Table S1). Almost a fifth of the Anopheles captured had fed on two or more host species in the same night (Table 3; Additional file 1: Table S1). This behaviour indicates that these species may not be persistent when feeding on a host, if disturbed they may move on to another host [23]. This type of behaviour has been observed in other vectors and it has been suggested that this is due to frequent biting, which may increase human risk to malaria infectious bites or zoonotic infections $[23,52,53]$.

The expected primary malaria vectors in this region would be those of the Anopheles punctulatus species complex, including An. farauti and An. punctulatus, both major malaria vectors from eastern Indonesia through Papua New Guinea [50, 51]. These two species represented a very small portion of the total catch in this experiment, only 3 of 1014 anophelines. The finding of a high sporozoite infection rate in $A n$. kochi (9\%) was surprising but may also be a function of a small sample size collected during a limited time period. Additional collections will be required to ascertain the importance of this or other species as malaria vectors in eastern Indonesia.

The peak collection of most of the species collected was early in the evening, around 19:00-20:00, when people are still very active and would likely not be protected under bed nets or indoors (Fig. 2). Though previous collections in this area also indicate that the Anopheles tend not to enter houses, it is even more unlikely that interventions such as bed nets or indoor residual spray would be as effective if the primary vectors are biting people early in the evening.

\section{Conclusions}

Further population genetic analysis is needed to determine whether subpopulations of a single species are feeding on different hosts, which has implications for 
sampling strategies. Interventions utilizing animals could be effective in monitoring vectors or reducing malaria transmission where vectors are outdoor feeding, frequently feeding, and more zoophilic or catholic than anthropophilic, as is suggested from the blood meal analyses presented here. This study also represents a single time point in the year during the peak season of malaria transmission. Longitudinal sampling through the year in multiple locations in Indonesia would be needed to examine the feasibility of using animal-baited tents to monitor malaria vectors and to better characterize species-specific host feeding behaviours.

\section{Additional file}

Additional file 1: Table S1. Bloodmeal identification of 968 mosquito abdomens by molecular species and host-baited tent. Bloodmeal source is denoted by letter: $\mathrm{C}$ for cow, $\mathrm{G}$ for goat, $\mathrm{H}$ for humans, $\mathrm{U}$ for unfed, and combination letters for multiple bloodmeals.

\section{Authors' contributions}

BSTL and NFL carried out the sequence analysis, interpretation of the data, and drafted the manuscript. BSTL, NFL, TRB, SS, FHC, and WAH contributed to the conception and design of the study. SZ, BSTL, SS, S, SF, and AB participated in the implementation of the study and entomological collections. DS, PBSA, BSTL, HCM, and SK participated in the molecular analysis, sequencing, and Plasmodium screening of field-collected specimens. BSTL and TAB did the statistical analysis and generated the figures. All authors contributed to the critical revision of the manuscript for intellectual content. All authors read and approved the final manuscript.

\section{Author details}

${ }^{1}$ Eck Institute for Global Health, University of Notre Dame, Notre Dame, IN, USA. ${ }^{2}$ Eijkman Institute for Molecular Biology, Jakarta, Indonesia. ${ }^{3}$ Centers for Disease Control and Prevention, Atlanta, GA, USA. ${ }^{4}$ Unicef, Jakarta, Indonesia. ${ }^{5}$ National Institute of Health Research and Development, Jakarta, Indonesia. ${ }^{6}$ Laboratory of Malaria and Vector Research, National Institute of Allergy and Infectious Diseases, National Institutes of Health, Bethesda, MD, USA. ${ }^{7}$ Australian Institute of Tropical Health and Medicine, James Cook University, Cairns, Australia.

\section{Acknowledgements}

Special thanks to field assistants, collectors, and laboratory assistants for specimen processing at the Eijkman Institute of Molecular Biology, Jakarta, Indonesia and the University of Notre Dame. Thanks to Julie Niedbalski and Katie Cybulski for help and support at the University of Notre Dame, and to Endang Sumiwi, Rita Kusriastuti and P. R. Arbani for their support.

\section{Competing interests}

The authors declare that they have no competing interests.

\section{Availability of data and materials}

This article is published Open Access. The datasets generated or analysed during the current study are available from the corresponding authors on reasonable request.

\section{Consent for publication \\ Not applicable.}

\section{Ethics approval and consent to participate}

The need for ethics approval for non-human subjects (which was determined to include performing human landing collections and using animal-baited tents) was waived by the University of Notre Dame. The State Minister for Research and Technology of The Republic of Indonesia approved the study in 2009 and also waived the need for a formal ethics review. HLCs and animal-baited trapping were performed under the supervision of Dr. Sukowati Supratman of the Indonesian National Institute of Health Research and Development.

\section{Funding}

This project was funded by the Bill and Melinda Gates Foundation under Grant No. 45114. The Malaria Transmission Consortium.

\section{Publisher's Note}

Springer Nature remains neutral with regard to jurisdictional claims in published maps and institutional affiliations.

Received: 2 May 2017 Accepted: 20 July 2017

Published online: 02 August 2017

\section{References}

1. WHO. World Malaria Report 2016. Geneva: World Health Organization; 2016.

2. Elyazar IRF, Gething PW, Patil AP, Rogayah H, Kusriastuti R, Desak M, et al, Plasmodium falciparum malaria endemicity in Indonesia in 2010. PLoS ONE. 2011:6:e21315.

3. WHO, SEARO. Anopheline species complexes in South and South-East Asia. New Delhi: Worth Health Organization, SEARO; 2007.

4. Foley DH, Rueda LM, Wilkerson RC. Insight into global mosquito biogeography from country species records. J Med Entomol. 2007:44:554-67.

5. Killeen GF. Characterizing, controlling and eliminating residual malaria transmission. Malar J. 2014;13:330.

6. The malERA Consultive Group on Vector Control. A research agenda for malaria eadication: vector control. PLoS Med. 2011;8:e1000401.

7. Day JF. Host-seeking strategies of mosquito disease vectors. J Am Mosq Control Assoc. 2005;21:17-22.

8. Kirnowordoyo S. Supalin. Zooprophylaxis as a useful tool for control of $A$. aconitus transmitted malaria in Central Java, Indonesia. J Commun Dis. 1986;18:90-4

9. Killeen GF, Mckenzie FE, Foy BD, Bøgh C, Beier JC. The availability of potential hosts as a determinant of feeding behaviours and malaria transmission by African mosquito populations. Trans R Soc Trop Med Hyg. 2001;95:469-76.

10. Burkot TR. Non-random host selection by Anopheline mosquitoes. Parasitol Today. 1988;4:156-62.

11. Snow WF. Studies of house-entering habits of mosquitoes in The Gambia, West Africa: experiments with prefabricated huts with varied wall apertures. Med Vet Entomol. 1987;1:9-21.

12. Lyimo IN, Ferguson HM. Ecological and evolutionary determinants of host species choice in mosquito vectors. Trends Parasitol. 2009;25:189-96.

13. Burkot TR, Dye C, Graves PM. An analysis of some factors determining the sporozoite rates, human blood indexes, and biting rates of members of the Anopheles punctulatus complex in Papua New Guinea. Am J Trop Med Hyg. 1989;40:229-34

14. Lefèvre T, Gouagna L, Dabiré KR, Elguero E, Fontenille D, Renaud F, et al. Beyond nature and nurture: phenotypic plasticity in blood-feeding behavior of Anopheles gambiae s.s. when humans are not readily accessible. Am J Trop Med Hyg. 2009:81:1023-9.

15. Garrett-Jones C. The human blood index of malaria vectors in relation to epidemiological assessment. Bull World Health Organ. 1964;30:241-61.

16. Service MW. A critical review of procedures for sampling populations of adult mosquitoes. Bull Entomol Res. 1977;67:343-82.

17. Govella NJ, Chaki PP, Mpangile JM, Killeen GF. Monitoring mosquitoes in urban Dar es Salaam: evaluation of resting boxes, window exit traps, CDC light traps, Ifakara tent traps and human landing catches. Parasit Vectors. 2011;4:40.

18. Fornadel CM, Norris LC, Norris DE. Centers for Disease Control light traps for monitoring Anopheles arabiensis human biting rates in an area with low vector density and high insecticide-treated bed net use. Am J Trop Med Hyg. 2010;83:838-42. 
19. Mathenge EM, Misiani GO, Oulo DO, Irungu LW, Ndegwa PN, Smith T, et al. Comparative performance of the Mbita trap, CDC light trap and the human landing catch in the sampling of Anopheles arabiensis, An. funestus and culicine species in a rice irrigation in western Kenya. Mala J. $2005 ; 4: 7$.

20. Kay BH, Boreham PF, Fanning ID. Host-feeding patterns of Culex annulirostris and other mosquitoes (Diptera: Culicidae) at Charleville, Southwestern Queensland, Australia. J Med Entomol. 1985;22:529-35.

21. Gillies MT. Experiments on host selection in the Anopheles gambiae complex. Ann Trop Med Parasitol. 1967;61:68-75

22. Kent RJ, Norris DE. Identification of mammalian blood meals in mosquitoes by a multiplexed polymerase chain reaction targeting cytochrome $\mathrm{B}$. Am J Trop Med Hyg. 2005;73:336-42.

23. Burkot TR, Graves PM, Paru R, Lagog M. Mixed blood feeding by the malaria vectors in the Anopheles punctulatus complex (Diptera: Culicidae). J Med Entomol. 1988;25:205-13.

24. Wekesa J, Yuval B, Washino R. Multiple blood feeding by Anopheles freeborni and Culex tarsalis (Diptera:Culicidae): spatial and temporal variation. J Med Entomol. 1997;34:219-25.

25. Mukabana WR, Takken W, Knols BGJ, Knols BGJ. Analysis of arthropod bloodmeals using molecular genetic markers. Trends Parasitol. 2002;18:505-9.

26. Kay BH, Boreham PFL, Edman JD. Application of the "feeding index" concept to studies of mosquito host-feeding patterns. Mosq News. 1979;39:68-72

27. Bugoro H, Cooper RD, Butafa C, Iro C, Mackenzie DO, Chen C, et al. Bionomics of the malaria vector Anopheles farauti in Temotu Province, Solomon Islands: issues for malaria elimination. Malar J. 2011;10:133.

28. Fritz ML, Siegert PY, Walker ED, Bayoh MN, Vulule JR, Miller JR, et al. Toxicity of bloodmeals from ivermectin-treated cattle to Anopheles gambiae s.l. Ann Trop Med Parasitol. 2009;103:539-47.

29. Foy BD, Kobylinski KC, Marques da Silva I, Rasgon JL, Sylla M. Endectocides for malaria control. Trends Parasitol. 2011:27:423-8.

30. Foley DH, Bryan J, Lawrence G. The potential of ivermectin to control the malaria vector Anopheles farauti. Trans R Soc Trop Med Hyg. 2000;94:625-8.

31. Sota T, Mogi M. Effectiveness of zooprophylaxis in malaria control: a theoretical inquiry, with a model for mosquito populations with two bloodmeal hosts. Med Vet Entomol. 1989;3:337-45.

32. Elyazar IRF, Hay SI, Baird JK. Malaria distribution, prevalence, drug resistance and control in Indonesia. Adv Parasitol. 2011;74:41-175.

33. Elyazar IRF, Gething PW, Patil AP, Rogayah H, Sariwati E, Palupi NW, et al. Plasmodium vivax malaria endemicity in Indonesia in 2010. PLoS ONE. 2012;7:e37325

34. O'Connor C, Soepanto A. Illustrated key to female anophelines of Indonesia. Jakarta: Directorate of Communicable Disease, Ministry of Health; 1989

35. Beebe NW, Saul A. Discrimination of all members of the Anopheles punctulatus complex by polymerase chain reaction-restriction fragment length polymorphism analysis. Am J Trop Med Hyg. 1995;53:478-81.

36. Burkot TR, Zavala F, Gwadz RW, Collins FH, Nussenzweig RS, Roberts DR. Identification of malaria-infected mosquitoes by a two-site enzymelinked immunosorbent assay. Am J Trop Med Hyg. 1984;33:227-31.

37. Singh B, Bobogare A, Cox-Singh J, Snounou G, Abdullah MS, Rahman HA. A genus- and species-specific nested polymerase chain reaction malaria detection assay for epidemiologic studies. Am J Trop Med Hyg. 1999;60:687-92.

38. R Core Team. R: a language and environment for statistical computing. 2016. https://www.r-project.org/.

39. Wickham H. ggplot2: elegant graphics for data analysis. 2009. http:// ggplot2.org.

40. Neuwirth E. RColorBrewer: ColorBrewer Palettes. 2014. https://cran.rproject.org/package $=$ RColorBrewer.

41. Elyazar IRF, Sinka ME, Gething PW, Tarmidzi SN, Surya A, Kusriastuti R, et al. The distribution and bionomics of Anopheles malaria vector mosquitoes in Indonesia. Adv Parasitol. 2013:83:173-266.

42. Stevenson J, St. Laurent B, Lobo NF, Cooke MK, Kahindi SC, Oriango RM, et al. Novel vectors of malaria parasites in the Western Highlands of Kenya. Emerg Infect Dis. 2012;18:1547-9.

43. Lobo NF, St Laurent B, Sikaala CH, Hamainza B, Chanda J, Chinula D, et al. Unexpected diversity of Anopheles species in Eastern Zambia: implications for evaluating vector behavior and interventions using molecular tools. Sci Rep. 2015:5:17952.

44. Govella NJ, Moore JD, Killeen GF. An exposure-free tool for monitoring adult malaria mosquito populations. Am J Trop Med Hyg. 2010;83:596-600

45. Taylor WRJ, Widjaja H, Basri H, Fryauff DJ, Ohrt C, Taufik E, et al. Assessing the ParaSight(r)-F test in northeastern Papua, Indonesia, an area of mixed Plasmodium falciparum and Plasmodium vivax transmission. Am J Trop Med Hyg. 2002;66:649-52.

46. Fryauff D, Soekartono Tuti S, Leksana B, Suradi Tandayu S, et al. Survey of resistance in vivo to chloroquine of Plasmodium falciparum and $P$. vivax in North Sulawesi, Indonesia. Trans R Soc Trop Med Hyg. 1998;92:82-3.

47. Prior A, Torr SJ. Host selection by Anopheles arabiensis and An. quadriannulatus feeding on cattle in Zimbabwe. Med Vet Entomol. 2002;16:207-13.

48. Gillies MT, Wilkes TJ. A comparison of the range of attraction of animal baits and of carbon dioxide for some West African mosquitoes. Bull Entomol Res. 1969:59:441-56.

49. Qiu YT, Smallegange RC, Hoppe S, van Loon JJA, Bakker EJ, Takken W. Behavioural and electrophysiological responses of the malaria mosquito Anopheles gambiae Giles sensu stricto (Diptera: Culicidae) to human skin emanations. Med Vet Entomol. 2004;18:429-38.

50. Cooper RD, Waterson DGE, Kupo M, Foley DH, Beebe NW, Sweeney AW. Anopheline mosquitoes of the western province of Papua New Guinea. J Am Mosq Control Assoc. 1997:13:5-12.

51. Cooper RD, Waterson DGE, Frances SP, Beebe NW, Sweeney AW. The Anopheline fauna of Papua New Guinea. J Am Mosq Control Assoc. 2006;22:213-21.

52. Amerasinghe $\mathrm{PH}$, Amerasinghe FP. Multiple host feeding in field populations of Anopheles culicifacies and An. subpictus in Sri Lanka. Med Vet Entomol. 1999:13:124-31.

53. Boreham PFL, Garrett-Jones C. Prevalence of mixed blood meals and double feeding in a malaria vector (Anopheles sacharovi Favre). Bull World Health Organ. 1973;48:605-14.

\section{Submit your next manuscript to BioMed Central and we will help you at every step:}

- We accept pre-submission inquiries

- Our selector tool helps you to find the most relevant journal

- We provide round the clock customer support

- Convenient online submission

- Thorough peer review

- Inclusion in PubMed and all major indexing services

- Maximum visibility for your research

Submit your manuscript at www.biomedcentral.com/submit
(OioMed Central 